\title{
MERCADOS PROTEGIDOS \\ Y CONSUMO DESIGUAL. \\ CUBA Y EL CAPITALISMO ESPAÑOL \\ ENTRE 1878 Y 1898 *
}

\author{
JOSÉ A. PIQUERAS ARENAS \\ Universidad Jaume I
}

\section{RESUMEN}

En el presente artículo se examina la evolución del intercambio comercial entre España y Cuba en el período de 1878 a 1898, las variaciones en el volumen y composición de las transacciones, así como su incidencia en el conjunto de las economías española y cubana, revisándose el impacto de las exportaciones peninsulares sobre el mercado colonial. Las conclusiones apuntan una sobrevaloración instrumental de la dominación mercantil antillana destinada a obtener ventajas en la política comercial española que, sin embargo, contribuyó a fomentar una conciencia de dependencia en vísperas de la guerra de emancipación.

\section{ABSTRACT}

This article examines the evolution of trade exchange between Spain and Cuba from 1878 to 1898 , the variations in the volume and composition of the transactions and their effect on Spanish and Cuban economies as a whole, reviewing the impact of peninsular exports on the colonial market. The conclusions point to an instrumental overvaluation of Antillas' mercantile domination aiming to obtain adventages in Spain's commercial policy, which nevert-

* Una primera versión del presente texto fue presentado como ponencia a la II Conferencia internacional «En torno a 1898. Época de transición», celebrado en La Habana en diciembre de 1995, para cuya asistencia se contó con una ayuda de la Generalitat Valenciana. La redacción final se ha beneficiado de la lectura crítica de Alejandro García Alvarez, Antonio Santamaria, Luis Miguel García Mora y de los evaluadores anónimos de la Revista de Historia Económica, a quienes agradezco sus observaciones y sugerencias. Las opiniones expresadas en el artículo son responsabilidad exclusiva del autor. 
heless helped to foster an awareness of dependence on the eve of the war
of independence.

\section{INTRODUCCIÓN}

Con frecuencia se ha querido explicar la evolución de Cuba de forma unilateral partiendo de dos circunstancias: la indudable potencialidad económica de la Isla y la ausencia de desarrollo en la Metrópoli. Lo uno y lo otro habrían propiciado que la colonia fuera estrechando sus relaciones comerciales primero con Inglaterra y más adelante con los Estados Unidos, mientras a España se le reservaba la función de garante de las relaciones sociales esclavistas y de la jerarquía racial establecida ${ }^{1}$. A cambio, el Estado español habría dispuesto de cierto número de lucrativos destinos con los que premiar a sus empleados civiles y militares, y las producciones peninsulares gozaron de un mercado privilegiado gracias a una política de aranceles fuertemente protectores que hizo de los cubanos unos consumidores cautivos de artículos españoles excedentarios poco competitivos a escala internacional ${ }^{2}$.

' Es la tesis suscrita por la historiografía cubana más acreditada. Véase Moreno Fraginals (1978), II, p. 132: «Incapacitada para explotar colonialmente a Cuba, [...] España se dedicó a esquilmarla. Es decir, inepta para establecer un sistema de explotación colonial al modo capitalista, para lo cual se requería un grado de desarrollo capitalista que España no tenía, optó por desenvolver una política de fuerza sobre la cual montó el mecanismo de expoliación»; Zanetti (1989), p. 18: «La incapacidad de España para someter a su colonia a un régimen de explotación moderno propiamente capitalista, redundó en la adopción de un esquema parasitario cuyo mecanismo fundamental de succión era [...] el régimen arancelario». Saiz Pastor (1988) ha discutido este modelo para la etapa isabelina, cuestionando que el sistema «neocolonial» no esquilmara los países sometidos, y ha integrado la explotación de la colonia en las necesidades capitalistas de la economía (protección de un mercado nacional integrado) y del liberalismo español (extracción fiscal y presupuestaria), centrando su investigación en este último aspecto (Saiz Pastor, 1994). La función de la colonia en la formación permanente de capitales españoles y su integración en las redes del capitalismo más desarrollado ha sido documentada por Bahamonde-Cayuela (1992).

2 Maluquer (1974), pp. 347: «el mercado antillano fue durante todo el siglo XIX para los géneros peninsulares excedentarios un mercado reservado, sujeto en algunos ramos a un auténtico monopolio. Esto resulta aún más importante si se observa que la mayoría de productos españoles de exportación carecían de competitividad en el mercado mundial». Zanetti (1975), p. 52: «... España ejerce en todo momento un férreo control sobre la actividad comercial cubana» con los objetivos de beneficiarse de las recaudaciones aduaneras y de «convertir el país en un destinatario obligado de sus excedentes agrícolas y de los productos de su incipiente industria. Ambos fines se materializan en una política virtualmente monopólica...»; Zanetti (1989), p. 12: «Los productos españoles, amparados en las preferencias arancelarias, mantuvieron la primacía en el mercado cubano.» 
Las visiones de las problemáticas relaciones entre España y Cuba, sin embargo, suelen descansar en una consideración estática de la Península: la economía, los intereses en Cuba, los gobernantes y las fracciones dirigentes de la Metrópoli vienen a entenderse a modo de realidades inmutables, fijadas en coincidencia con el tránsito a la economía de plantación a comienzos del siglo XIX. El análisis que proponemos consiste en un estudio de coyuntura entre el final de la primera guerra de emancipación en 1878 y el comienzo de la segunda y definitiva guerra de independencia en 1895, que permita situar los cambios introducidos en la esfera mercantil en una tendencia larga comprensiva de la segunda mitad del siglo xxx, al objeto de precisar la situación económica en las décadas que conducen al fin del dominio español.

Tomando como referencia principal las balanzas comerciales españolas en su relación con $\mathrm{Cuba}^{3}$, deteniéndonos en las exportaciones peninsulares con destino a la Isla, examinando las características de los artículos objeto de intercambio y contrastando esa información con la aportada por monografías publicadas en los últimos años -tanto sobre ciertas producciones como acerca de la evolución de la economía española- nos proponemos discutir que Cuba, gracias a la política arancelaria desplegada por la Metrópoli y por más que lo pretendiera, llegara a significar entre 1878 y 1895 un mercado capturado por la Península, si por esto entendemos el acaparamiento del mercado de bienes de consumo con artículos faltos de competitividad y con un sobreprecio respecto a otros de iguales condiciones y diferente procedencia.

En la etapa histórica a la que hacemos referencia la cautividad del mercado antillano supuso un argumento que no exigió demasiada demostración dada la patente cautividad política de la colonia. La denuncia fue utilizada de forma reiterada por quienes desde la Isla alentaron una política comercial que antepusiera los intereses económicos cubanos a los derivados de la condición dependiente del territorio y, en consecuencia, reclamaban que estuviera más abierta a los Estados Unidos. Naturalmente la denuncia fue también esgrimida por quienes abogaban por la independencia de las Antillas. Con posterioridad ha sido un recurso

${ }^{3}$ La información comercial en que se basa el presente análisis procede, salvo indicación en contra, de la Dirección General de Aduanas, Estadística general del Comercio exterior, 1868-1897. 
incorporado por la historiografía nacionalista cubana desde los primeros tiempos de la República a nuestros días ${ }^{4}$.

Al mismo tiempo, la tesis de la cautividad ha servido para construir uno de los tópicos más eficaces y persistentes de nuestra historiografía: la dependencia económica española del mercado antillano en las postrimerías del Ochocientos, igualmente publicitada por los productores peninsulares de la época que reclamaban ventajas oficiales y sobredimensionaban la importancia de las colonias para la supervivencia de la industria y la agricultura nacionales. A nuestro entender, la tesis y la explicación confunden el valor mercantil global de las posesiones ultramarinas con dos factores distintos: 1) la ventaja de disponer de mercados privilegiados en una época de creciente protección internacional, utilizada como instrumento de negociación de convenios bilaterales, y 2) la conveniencia de contar con una demanda más amplia que la peninsular para superar un estancamiento coyuntural o favorecer un proceso de tranformación empresarial. En última instancia, a tenor de la información disponible, tesis y explicación confundirían lo que no dejaron de ser aspiraciones peninsulares y resultados verificables.

\section{REEXAMINANDO LAS BALANZAS: GRANDES CIFRAS Y TENDENCIAS}

\section{El mercado peninsular}

La etapa de la Restauración que se inicia en España en 1875 coincide con un período de crecimiento económico basado en el desarrollo de la industria de bienes de consumo, el sector siderúrgico, el desarrollo de los transportes marítimos y el auge de las exportaciones agrícolas y mineras. Febre d'or calificaron a los primeros años en Cataluña. País capitalista, el atraso relativo no implicó la ausencia de dinamismo económico, puesto de relieve en la coyuntura restauracionista dentro de una tendencia iniciada a mediados de siglo. Veamos: entre 1860 y 1890 el Producto Interior Bruto

${ }^{4}$ El ejemplo de Roig de Leuchsenring (1949), pp. 151-155, basándose en textos autonomistas e independentistas de la época, harto reproducidos por lo demás. El autor desconocía la existencia de las balanzas comerciales españolas y señalaba la dificultad de reconstruir el comercio exterior cubano más que de modo fragmentario. De manera contradictoria con su argumentación, las cifras que ofrece muestran una suerte de imperfecto duopolio proveedor a la Isla de España y Estados Unidos, en el que este país toma ventaja en 1894 . 
español experimenta un incremento del orden del 76 por 100; el producto por habitante crece en España entre esas mismas fechas un 56 por 100. La renta per cápita habría pasado de 380,1 pesetas (pesetas constantes de 1913) a 511,6, lo que representa un aumento del 35 por 100 en treinta años ${ }^{5}$. Estamos, pues, ante un país que conoce un crecimiento sostenido del producto y de la renta.

A la vista de estas últimas magnitudes, hasta ahora no contempladas al examinar las relaciones comerciales entre España y sus posesiones, debiera replantearse la versión sobre el estancamiento del mercado metropolitano en las últimas décadas de relación colonial como una de las causas del distanciamiento económico de la mayor de las Antillas. Por el contrario, el mercado peninsular se hallaba en proceso de ampliación como lo prueba el incremento de la renta y lo confirma el aumento de las importaciones -al menos hasta 1892- de un artículo tan elástico como el azúcar, pese al desarrollo simultáneo de la producción autóctona. Que ese crecimiento no repercutiera en la demanda de productos antillanos (gráfico 1) es otra cuestión que merece un análisis aparte. A la altura de los años ochenta el problema de la comercialización del azúcar cubano radicaba en la sobreproducción mundial, la caída de los precios internacionales y en la desaparición del mercado europeo; y quizás en un lugar secundario, en la capacidad de consumo de la metrópoli, cuyo abastecimiento disputó con éxito la industria peninsular.

Las importaciones procedentes de Cuba cayeron en la Península durante la Guerra de los Diez Años y sólo se recuperaron significativamente durante el período de la guerra del 95. La sustitución de productos coloniales cubanos por los de Puerto Rico y Filipinas queda registrada en las estadísticas comerciales: de aportar el 83,4 por 100 en 1865-1869, Cuba pasa a representar el 48,5 por 100 de las importaciones coloniales españolas en 1880-1885, para mantenerse después en torno al 50 por 100 (cuadro 1). Al margen de la estrechez del mercado metropolitano, en proceso de ampliación - aunque no lo advirtiera la publicística cubana de la época ni lo haya tenido siempre presente la historiografía posterior-, las producciones cubanas encontraron la competencia del tabaco y el azúcar de procedencia boriqueña y filipina, al tiempo que la desaparición del café

"Prados (1988), p. 45 para el PIB; p. 51 para el producto por habitante. La renta per cápita en Prados (1982), p. 68; otros autores, como Albert Carreras, matizan este crecimiento para dejarlo en el 25 por 100 . A nuestros efectos la diferencia no modifica el cuadro general. Tampoco modifica la tendencia apuntada que otros países europeos conocieran un crecimiento mayor en esa misma época. 


\section{GRÁFICO 1}

\section{Comercio colonial. Importaciones de Cuba y renta nacional española}

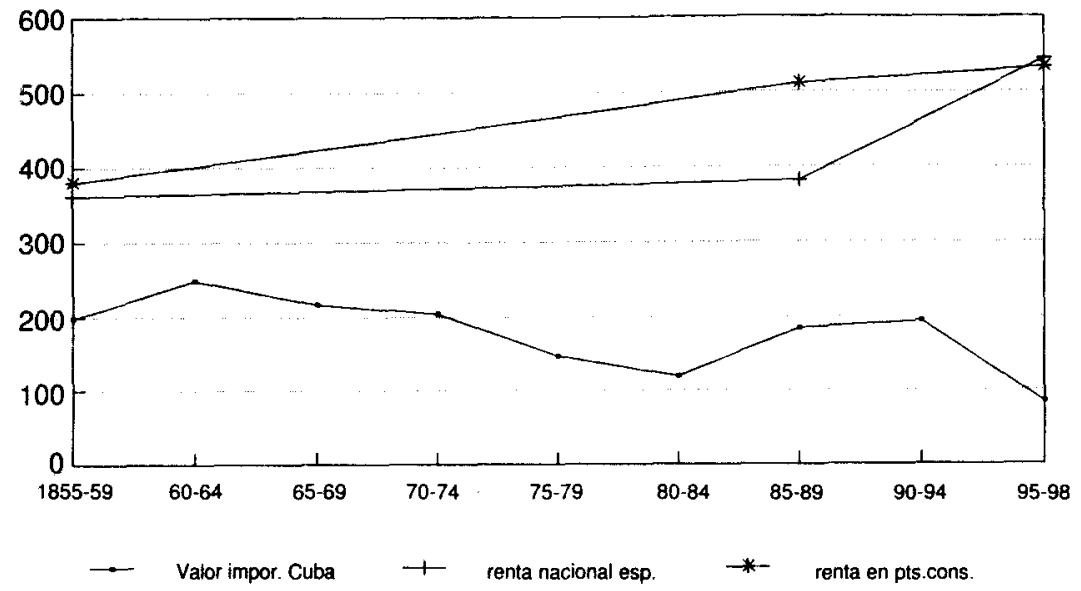

Import en millones pts.

Renta en pls. per cápita

dejó esa producción en manos de la pequeña Antilla, lo que mejoraba su balanza con la Península. Cuba se encontró además, como antes se ha apuntado, con el efecto de la caída del precio del azúcar.

Una primera constatación respecto a la pérdida relativa de influencia del comercio colonial cubano en España señala mayor volumen comercial a menor precio y con destino a una economía metropolitana en la que el comercio exterior se ha multiplicado en pocos años. Si en el quinquenio 1855-59 las importaciones de origen cubano representan para España el 12,2 por 100 de sus importaciones totales, cuatro décadas después representan el 4,5 por 100. Ahora bien, en términos absolutos el volumen comercial no cesó de incrementarse en cuantía y valor; entre 1866 y 1894 las importaciones procedentes de Cuba aumentaron su valor un 106 por 100 , habiendo conocido proporciones mejores a lo largo de esa etapa ${ }^{6}$.

"Dirección General de Aduanas, Estadística general del Comercio exterior, 1866 y 1894. Los máximos valores en las importaciones de procedencia cubana fueron alcanzados en $1892(172,5$ por 100 sobre 1866$), 1890$ y 1885 . 


\section{CUADRO 1}

Las colonias en el comercio exterior de España

(Porcentaje del valor total de la balanza comercial)

\begin{tabular}{|c|c|c|c|c|c|c|}
\hline \multirow{2}{*}{ Años } & \multicolumn{3}{|c|}{ Exportaciones } & \multicolumn{3}{|c|}{ Importaciones } \\
\hline & Colonias & Cuba & Resto & Colonias & Cuba & Resto \\
\hline $1855-59$. & 21,1 & 19,4 & 1,7 & 14,5 & 12,2 & 2,3 \\
\hline $1860-64 \ldots$ & 20,9 & 19,5 & 1,4 & 12,7 & 11,2 & 1,5 \\
\hline $1865.69 .$. & 19,8 & 18,5 & 1,3 & 12,5 & 10,4 & 2,7 \\
\hline $1870-74 .$. & 15,1 & 13,9 & 1,2 & 9,5 & 7,6 & 1,9 \\
\hline $1875-79 \ldots \ldots \ldots \ldots \ldots \ldots \ldots$ & 17,1 & 15,2 & 1,9 & 8,1 & 5,3 & 2,8 \\
\hline $1880-84 \ldots \ldots \ldots \ldots \ldots \ldots$ & 11,5 & 9,1 & 2,4 & 6,6 & 3,2 & 3,4 \\
\hline $1885-89 \ldots \ldots \ldots \ldots \ldots \ldots$ & 11,5 & 9,0 & 2,5 & 9,3 & 4,7 & 4,6 \\
\hline 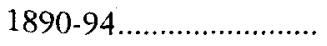 & 19,8 & 14,7 & 5,7 & 9,4 & 4,5 & 4,9 \\
\hline $1895.99 \ldots \ldots \ldots \ldots \ldots \ldots \ldots \ldots \ldots \ldots \ldots$ & 24,0 & 16,8 & 7,2 & 11,7 & 6,2 & 5,5 \\
\hline
\end{tabular}

Fuente: Elaborado a partir de Prados (1982), pp. 48 y $57^{7}$.

NOTA: La columna de las colonias agrupa el comercio peninsular con Cuba, Puerto Rico y Filipinas.

A partir de 1878 España comenzaba a ser menos metrópoli respecto a Cuba de lo que antes hubiera sido: su economía, en conjunto, estuvo menos orientada que en cualquier etapa anterior por el mercado cubano o por las producciones de la colonia. De un lado se ha reducido porcentualmente la balanza comercial en las dos direcciones, y de otro las rentas aduaneras de Cuba quedaron condicionadas por la función de soportar la garantía de la Deuda. Lo cual no significa que perdiera interés para el capital financiero o el transporte marítimo, ni supone ignorar que en la última década, desde 1887 y sobre todo a partir de 1891 , se incrementaron sobremanera las exportaciones textiles a la Isla.

Lo que después del Zanjón se hizo más evidente es que sería imposible la reciprocidad que permitiese transitar a un modelo de relaciones neocoloniales, que antecede y acompaña la transición al imperialismo. Y aquí por «reciprocidad» no nos referimos al marco regulador de los intercambios, sino al contenido de los mismos y muy en particular a las características de la oferta cubana que por volumen y naturaleza era difícil

7 Nos basamos en esta fuente en lugar de hacerlo directamente en la Estadistica general del Comercio exterior por comprender una serie de mayor duración que la registrada en nuestro estudio, que permite insertar las décadas $1878-98$ en la secuencia de la segunda mitad del siglo xIX. 
que pudiera ser absorbida por el mercado peninsular, o esperar de éste que actuara de intermediario en el proceso de comercialización exterior ante el desarrollo de la producción azucarera europea y las medidas adoptadas para protegerla. Las dificultades para que España pasara a desempeñar ese papel no vendrían tanto por la ausencia de desarrollo capitalista como por la orientación del desarrollo que suele cuestionarse ${ }^{8}$. El análisis coyuntural resulta en ese sentido muy ilustrativo.

\section{El peso de Cuba en el comercio exterior español de exportación}

El declive en términos relativos del comercio hispano-cubano es patente desde el comienzo de la Guerra de los Diez Años. Aunque el valor absoluto de las mercancías exportadas a Cuba se haya multiplicado por 1,4 entre los quinquenios $1855-59$ y $1875-79$, en realidad supuso una pérdida del 25 por 100 en el conjunto del comercio exterior español, como se aprecia en el cuadro 1. Durante los años 1870 y $1880 \mathrm{el}$ auge del comercio exterior español está relacionado con el entorno europeo más próximo y desarrollado, y consiste fundamentalmente en la exportación de minerales, metales y vino.

El análisis comparado de la evolución del comercio exterior español de exportación y de las exportaciones españolas a Cuba confirman un bajo coeficiente de correlación entre ambos desde los años 1870, excepto a mediados de la década de 1880 y durante las guerras coloniales. Este coeficiente permite medir la incidencia de la demanda cubana en el crecimiento de la exportación española (cuadro 2).

En términos de balanza comercial, Cuba actúa sobre la demanda exterior de forma paradójica cuando pugna por emanciparse: la guerra favorece los negocios en Ultramar en los quinquenios 1868-72 y 1893-97, tanto en el sector de transporte marítimo como en el mercantil, que es del que nos ocupamos, cuando el Ejército se convierte en el primer destinatario de las mercancías y se reducen las vías de importación en Cuba, de manera destacada las originadas en los Estados Unidos.

${ }^{8}$ Los condicionantes de la economía española no deben confundirse con la ausencia de ambiciones coloniales en los albores imperialistas. Las futuras empresas en el norte de África, sin dar tiempo a cicatrizar la herida antillana, ratifican esa vocación exterior de un capitalismo que no se resignaba al recogimento que le impuso la capitulación de París. Véase esta cuestión con amplitud en Hernández Sandoica (1982). 


\section{CUADRO 2}

Exportaciones a Cuba y comercio exterior español

\begin{tabular}{|c|c|}
\hline Quinquenio & Coeficiente de correlación \\
\hline $1868-1872 .$. & $+0,8608$ \\
\hline .............................. & $-0,2319$ \\
\hline $1878-1882$ & $+0,2057$ \\
\hline $1883 \cdot 1887 \ldots \ldots \ldots$ & $+0,7995$ \\
\hline $1888-1892 \ldots$ & $+0,1670$ \\
\hline 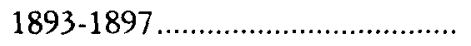 & $+0,9760$ \\
\hline
\end{tabular}

FuENTE: Dirección General de Aduanas, Estadistica general del Comercio exterior, 1868-1897.

Variables de la correlación: total de exportaciones españolas y exportaciones españolas a Cuba.

Entre 1878 y 1893 , período de entreguerras durante el cual la Metrópoli habría creado condiciones especiales para capturar el mercado colonial, imposibles de soportar para la población insular, únicamente la correlación de $1883-1887$ se presenta alta. Son años depresivos para la economía española, cuando los sectores peninsulares en dificultades consiguen las Leyes de Relaciones Comerciales de 1882 y obtienen el cabotaje entre Cuba y España, si bien con un sentido unilateral que burla las demandas de la burguesía antillana ${ }^{9}$. No obstante conviene destacar que la mejoría en la correlación de este periodo viene favorecida por un doble movimiento: auge de los envíos a Cuba pero también descenso del comercio exterior español en su conjunto (gráfico 2).

Sucede, sin embargo, que también fueron años de crisis económica en la Isla por lo que la importancia relativa de las exportaciones peninsulares a Cuba representaron un crecimiento neto en la balanza importadora de la mayor de las Antillas cuando desde 1868 España, con algo más de un tercio de cuota del mercado cubano, había pasado a convertirse en su primer proveedor tras desplazar a los Estados Unidos a una segunda posición.

" Las Leyes de Relaciones Comerciales de 1882 estipularon la reducción escalonada de los derechos de importación en Cuba para las producciones peninsulares hasta su desaparición en 1891; preveía otro tanto respecto a los productos cubanos a su entrada en la Península, con tres excepciones que destruían la reciprocidad: el azúcar, el tabaco y el café. 


\section{GRÁFICO 2}

Exportaciones españolas. Incidencia cubana

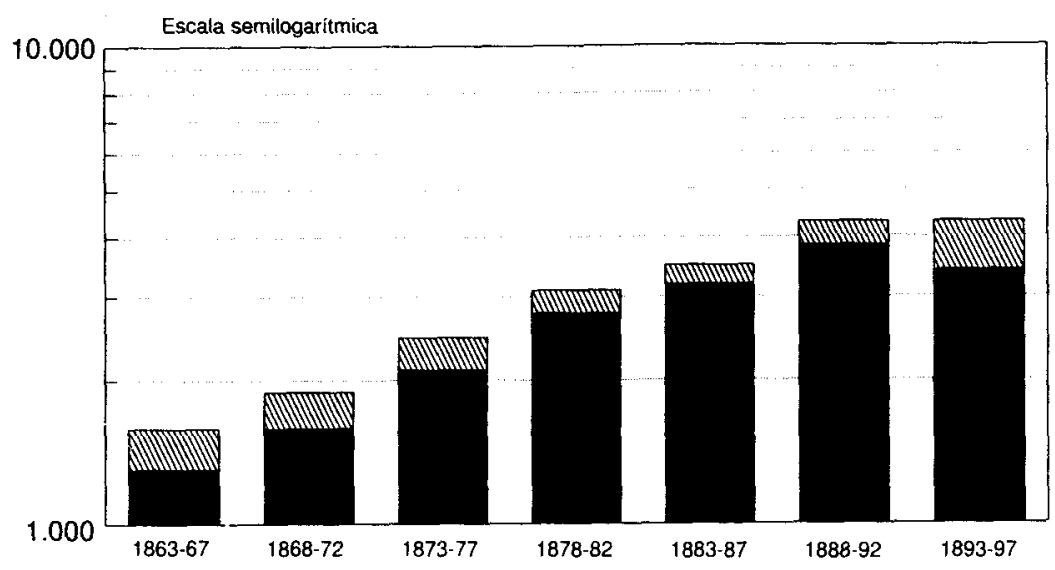

Valor en miles. ptas.

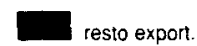

Mivili expont a Cuba

Ante la dimensión de la crisis interna, con baja de precios del azúcar y pérdida de mercados internacionales, cuyos efectos se vieron ampliados por la crisis monetaria y financiera que se cierne sobre la economía cubana en los años 1880, surgieron voces desde los círculos económicos reprobando la ausencia de colaboración de la metrópoli en la resolución de los problemas de la colonia. Y ello a pesar de que las autoridades españolas reaccionaron con la supresión del derecho diferencial de bandera y del derecho de exportación que gravaba el comercio exterior, con la reducción de aranceles y con la negociación de tratados internacionales de aplicación específica en la Isla como el modus vivendi suscrito con los norteamericanos en 1884, o acuerdos españoles extensivos a Cuba, como la consideración de nación más favorecida a diversos países europeos. Medidas todas ellas juzgadas insuficientes por el sector hacendado y exportador que reclamaban la apertura del mercado peninsular y, sobre todo, un tratado estable con los Estados Unidos que facilitara las exportaciones a ese destino aunque para ello debieran hacerse las concesiones exigidas por la potencia del norte. 
Ésta sería la principal base de las protestas criollas, desviadas hacia la creciente relevancia de las importaciones peninsulares en una época de dificultades internas como consecuencia de la caída de los precios de su principal producto de exportación. Precisamente la reducción del margen de beneficios fue, en nuestra opinión, el factor determinante en el próximo curso de los acontecimientos y en la reconsideración del papel que a ojos de diversos sectores políticos y sociales desempeñaba España en el destino de la Isla.

\section{DEMANDA COLONIAL Y CAPITALISMO ESPAÑOL}

En las décadas finales del siglo xIX el mercado colonial permitió incorporar al capítulo exportador español una serie de manufacturas hasta entonces ausentes de los apartados significativos de la balanza exterior. Se trata de producciones diversificadas que con excepción de los tejidos $y$, en parte, el papel descansan sobre la industria tradicional todavía no mecanizada, lo cual no debiera ser óbice para que esa demanda contribuyera a su desarrollo.

Se ha señalado que el mercado colonial salvó la crisis del sector textil algodonero hacia 1886 y que las exportaciones de tejidos representaron un 37,8 por 100 del incremento de la producción de esta industria entre los quinquenios $1875-79$ y 1893-97. El mercado colonial contribuyó además a reorientar en cierto modo dicho sector, pues si en 1885 apenas exportaba el 3 por 100 de la producción, en 1891 destinaba el 13 por 100 al mercado exterior, proporción que no cesó de crecer hasta alcanzar el 20 por 100 en 1898. La demanda colonial se produjo cuando la crisis del mercado interior amenazó seriamente a la industria nacional, catalana en su mayor parte.

La pérdida del imperio supuso un revés para los algodoneros, lo que ha sido tomado como indicativo de la sobreprotección precedente. No obstante en 1909 el sector casi había recuperado los niveles exportadores anteriores a 1898: había abierto mercados en Argentina, Francia, Turquía, Uruguay, Colombia, y otros países americanos, mientras conservaba en Cuba una cuota que convertía a la nueva República en el primer destino de sus producciones, en torno al 42 por 100 del volumen que había remitido 
a la Isla en 1894 , en vísperas del inicio de la guerra ${ }^{10}$. ¿Cómo explicar que si hasta 1898 la venta de textiles se justifica por el arancel, desaparecido éste se conservase una cuota de mercado tan destacada, cuando la «americanización» de la Isla está en pleno apogeo? La persistencia de redes comerciales en manos de españoles no parece razón suficiente, porque en tiempos de la colonia existía también un sector mercantil dedicado a la importación de textiles de otros países que acaparaba más de un tercio del mercado y cabe pensar que después del 98 se habría desarrollado al disponer de mejores condiciones para comerciar con sus proveedores europeos y norteamericanos. $Y$ en cualquier caso, esas redes mercantiles vendrían a explicar la subsistencia de la oferta pero no del consumo, muy probablemente guiado por el precio y el gusto, pues no debemos olvidar que la inmigración de procedencia española no cesó con la independencia de Cuba y que en el censo de 1907 la población de origen español superaba los 200.0000 habitantes y se situaba por encima del 11 por 100 del total de la Isla ${ }^{11}$.

Hay indicios suficientes para pensar que el quebranto del sector textil algononero en el 98 se debió antes a los efectos de la desaparición de un mercado consolidado, como consecuencia del desenlace de la guerra, que a las características de los artículos comercializados, que volvieron a encontrar salida, es muy posible que compitiendo en el segmento de mercado inferior en calidad y precio, y de clientes de menor poder adquisitivo, al que se había dirigido en Cuba.

El calzado de piel importado en Cuba de origen peninsular procedía en su mayor parte de Mallorca. Tenía un precio bajo, tanto por su calidad mediocre como por los reducidos costes de elaboración, en una industria poco mecanizada que apenas aprovechó la demanda para dotarse de estructura empresarial y maquinaria ${ }^{12}$. A diferencia de las importaciones de calzado norteamericano, el procedente de España estaba destinado a las clases populares, consumidoras además de alpargatas.

En cuanto al papel, el destinado a escribir procedía en su mayoría de Cataluña, mientras el papel de fumar se fabricaba en una localidad del País Valenciano, Alcoy. La demanda cubana de los años 1880 y 1890

10 La incidencia de la exportación en el incremento de producción, en Prados (1982), p. 72. Los efectos de la demanda colonial sobre una industria textil en crisis, en Sudrià (1983), pp. 371-373; la evolución del sector con posterioridad a 1898 , en p. 379 y tablas pp. 383-385.

$"$ La población, en Maluquer (1992), p. 127.

12 Nadal (1994), pp. 321 y ss. 
posibilitó la mecanización de esta última industria mediante fabricación continua, no así de la catalana, que mantuvo la fabricación manual mediante tinas pero comenzó a introducir máquinas picardo ${ }^{13}$. El papel de fumar tenía también otras salidas en América: pequeñas remesas se reexpedían de La Habana a Veracruz y Colón ${ }^{14}$, al margen de las exportaciones directas desde la Península; el mercado cubano de este subsector sobrevivió al 98.

La incidencia de la demanda colonial sobre las manufacturas españolas, como se ve, es diversa según los casos. En todos ellos supuso la ampliación del mercado interior y contribuyó a mantener actividades de bajo nivel técnico y empresarial (pieles adobadas, jabón, velas, alpargatas), alguna de las cuales iniciará su transformación en los años siguientes, en parte con los beneficios obtenidos en América.

La importancia de Cuba y Puerto Rico para la economía española en los años que van de 1878 a 1898 habrá de medirse, más que por el volumen absoluto de intercambios, por su incidencia en sectores que atravesaban una situación singular, bien por una crisis coyuntural o por hallarse en un proceso de transformación. Precisamente esta última es la circunstancia que caracteriza al sector en donde con más claridad se muestra el proceso y la aportación colonial al capitalismo español de la última etapa: el naviero. Como ha puesto de relieve J. M. Valdaliso, el comercio transoceánico con las Antillas contribuyó de forma decisiva a amortizar la inversión en capital fijo en el costoso proceso de conversión de la flota mercante española de la navegación a vela en navegación a vapor ${ }^{15}$. Pero es ésta una cuestión cuyas implicaciones desbordan las posibilidades de las presentes páginas.

\section{LA METRÓPOLI, ¿̇BENEFICARIA DEL COMERCIO EXTERIOR CUBANO?}

De forma quizá un tanto inadvertida ha llegado a formularse una interpretación sobre la función de la política arancelaria-comercial practicada por España en Cuba después del Zanjón: al cerrar a la colonia en 1882 el mercado peninsular para el azúcar, el tabaco y el café, excluyendo estos productos de las rebajas arancelarias previstas en las Leyes de

${ }^{13}$ Gutiérrez i Poch (1994), pp. 351-352.

${ }^{14}$ Archivo Nacional de Cuba, Fondo Aduanas de La Habana, núms. 231 y 232. Buques y mercancías que se exportan por el muelle de Caballería, 1884-1887.

15 Valdaliso (1991), p. 337. 
Relaciones Comerciales, España le estaría obligando a buscar otros mercados, en concreto el norteamericano; el superávit cubano generado en sus relaciones con los Estados Unidos habría servido para alentar la importación de bienes peninsulares gracias a los aranceles protectores que reservaban a la Metrópoli el mercado antillano ${ }^{16}$.

Estamos ante una hipótesis que merece ser discutida, al menos por dos razones. En primer lugar porque introduce en el cuadro del comercio dos variables por lo común analizadas por separado (el flujo exportador de Cuba a Estados Unidos y las importaciones peninsulares) o a lo sumo como exponentes de la balanza exterior cubana. En segundo término porque nos recuerda el formidable superávit comercial cubano con los Estados Unidos y lleva a interrogarnos por las prácticas importadoras derivadas del incremento de la renta de la Isla, de modo que podamos conocer mejor la economía beneficiada por una mayor demanda cubana.

La consideración de esta hipótesis, sin embargo, no despeja una cuestión previa: la existencia de una política arancelaria deliberada, orientada a los fines indicados, de la que no tenemos constancia. En caso de no haber existido dicha estrategia, la búsqueda del mercado norteamericano sería el resultado de la imposibilidad de proporcionar a Cuba la reciprocidad que exigía su potencia exportadora.

Resulta oportuno comprobar en qué medida el superávit del comercio cubano con los Estados Unidos se orientó a la importación de bienes peninsulares. Mientras el superávit del comercio Cuba-USA puede situarse en torno a los 43 millones de dólares en el quinquenio $1885-89$, el déficit con España se cifra en unos 6 millones. En el quinquenio 1890-95 las magnitudes habrían pasado a 50 millones y a unos 15 , respectivamente. La tendencia indica que el incremento del superávit del comercio cubano-norteamericano estuvo acompañado de un volumen mayor de importaciones desde España, sobre todo a partir de 1890. No es nada nuevo: la balanza comercial altamente excedentaria de Cuba estuvo siempre en la base de la explotación colonial española ${ }^{17}$. Los informes consulares de Estados Unidos destacaron en más de una ocasión cómo España se aprovechaba del comercio cubano-norteamericano a través de la Isla gracias al sistema proteccionista (aranceles y derecho diferencial) ${ }^{18}$. Sabemos,

\footnotetext{
${ }^{16}$ Insinuado por Moreno Fraginals (1978), II, p. 137.

${ }^{17}$ Moreno Fraginals (1978), II, p. 186. Las cifras anteriores son estimativas y proceden del gráfico publicado por este autor, III, p. 87, sin tablas ni fuentes específicas.

${ }_{18}$ State Departament. Archives: Consular Despatches-Havana, informes del vicecónsul Williams al subsecretario Seward, 8 de agosto y 12 de septiembre de 1878 , cit. por Portell
} 
además, que a la Península revierte por vía mercantil sólo una parte de los ingresos cubanos y que había otras vías para canalizar la renta colonial, como las remesas de la emigración temporal a Cuba que se intensifica en las décadas de $1880-1890^{19}$, los fletes y otros «invisibles».

Sin embargo, el superávit de Cuba con los Estados Unidos no puede ser trasladado directamente al déficit con España, ya que el incremento de importaciones norteamericanas enjugó de manera señalada las exportaciones hacia aquel país. La información disponible (cuadro 3) apunta que el incremento de las exportaciones cubanas a los Estados Unidos, favorecidas por el Tratado de 1891 (un crecimiento del 43 por 100 en 1891-94 sobre 1887-90), repercutió en la demanda de productos españoles en proporción similar a lo que crecieron las ventas al mercado del norte. La tasa de cobertura de unas por las otras —el porcentaje que las importaciones de España representaban de los ingresos por exportaciones cubanas a Norteamérica- experimentó una pequeña variación (del 28,7 al 31,25 por 100 de media en los años indicados), que no resulta significativa ya que es inferior a las oscilaciones habituales en años anteriores al auge exportador.

El crecimiento de las exportaciones españolas a Cuba no parece obedecer a la hipótesis que discutimos. Aunque éstas se beneficien del incremento de la renta cubana gracias a su flujo exportador, tienen su raíz en las Leyes de Relaciones Comerciales de 1882 y en la modificación de la estructura mercantil, en la que adquieren relevancia artículos de mayor valor. Así, el movimiento ascendente del valor de la exportación peninsular comienza en 1886 cuando se eleva de algo más de 58 millones de pesetas a 69; la recaída de 1887 es transitoria y comienza a recuperase en 1888 en una tendencia creciente hasta 1896 sin un solo retroceso (véase la serie de números índices del cuadro 3). Conviene subrayar que en 1886 faltaban seis ejercicios para que entrara en vigor el Tratado con los Estados Unidos que, sin embargo, dio impulso al proceso hasta sostenerlo en proporción a las exportaciones cubanas hacia los Estados Unidos, como se constata en la representación semilogarítmica del gráfico 3.

Vila (1939), III, p. 23. Obsérvese no obstante que la denuncia norteamericana se producía al término de la guerra, cuando el mercado estadounidense había pasado a absorber la mayor parte de las exportaciones cubanas y habían sido desplazados por la Península del primer puesto como suministradores de la Isla.

${ }_{19}$ Maluquer (1992), pp. 49 y ss.: entre 1882 y 1899 llegaron 524.658 españoles y retornaron 427.185. Falta evaluar el monto de las transferencias; García López (1992) ha descrito sus mecanismos y ha comenzado a efectuarlas, destacando su importancia a partir de 1880 (pp. 95 y ss.). 


\section{CUADRO 3}

Comercio Cuba/Estados Unidos y Cuba/España.

La compensación de las balanzas

\begin{tabular}{|c|c|c|c|c|c|c|}
\hline \multirow{2}{*}{ Años } & \multicolumn{2}{|c|}{$\begin{array}{c}\text { Exportación } \\
\text { Cuba a EEUU }\end{array}$} & \multicolumn{3}{|c|}{$\begin{array}{c}\text { Exportación } \\
\text { España a Cuba }\end{array}$} & \multirow{2}{*}{$\begin{array}{c}\text { Cobertura } \\
\text { exportación } \\
\text { Cuba/Esp. } \\
(3 / 1) \\
\text { (porcentoje) }\end{array}$} \\
\hline & $\begin{array}{c}\text { (dólares) } \\
\text { (1) }\end{array}$ & $\begin{array}{l}\text { Num. } \\
\text { indice }\end{array}$ & $\begin{array}{c}\text { (pesetas) } \\
(2)\end{array}$ & $\begin{array}{c}\text { (dólares) } \\
\text { (3) }\end{array}$ & $\begin{array}{l}\text { Nüm. } \\
\text { indice }\end{array}$ & \\
\hline 1875. & 64.587 .717 & 113,5 & 85.806 .000 & 17.161 .200 & 140,9 & 26,6 \\
\hline $1876 \ldots$ & 56.007 .866 & 98,4 & 69.138 .000 & 13.827 .500 & 113,5 & 24,7 \\
\hline 1877. & 65.828 .395 & 115,7 & 81.731 .000 & 16.346 .200 & 134,2 & 24,8 \\
\hline 1878. & 56.901 .332 & 100 & 60.884 .993 & 12.176 .998 & 100 & 21,4 \\
\hline 1879. & 63.649 .656 & 111,8 & 68.294 .076 & 13.658 .815 & 112,2 & 21,5 \\
\hline 1880. & 65.423 .018 & 114,9 & 70.270 .311 & 14.054 .062 & 115,4 & 21,5 \\
\hline $1881 \ldots$ & 63.003 .404 & 110,7 & 58.853 .730 & 11.770 .746 & 96,6 & 18,7 \\
\hline 1882. & 70.450 .652 & 123,8 & 67.633 .198 & 13.526 .639 & 111,1 & 19,2 \\
\hline 1883. & 65.544 .534 & 115,2 & 59.071 .661 & 11.814 .332 & 97,0 & 18,0 \\
\hline $1884 \ldots$ & 57.181 .497 & 110,5 & 52.778 .264 & 10.555 .652 & 86,7 & 18,5 \\
\hline $1885 \ldots$ & 42.306 .093 & 74,3 & 58.381 .029 & 11.676 .205 & 95,9 & 27,6 \\
\hline $1886 \ldots$ & 51.110 .780 & 89,8 & 69.015 .742 & 13.803 .148 & 113,3 & 27,0 \\
\hline 1887. & 49.515 .434 & 87,0 & 60.857 .330 & 12.171 .466 & 99,9 & 24,6 \\
\hline $1888 \ldots$ & 49.319 .087 & 86,7 & 65.096 .728 & 13.019 .345 & 106,9 & 26,4 \\
\hline 1889. & 52.130 .623 & 91,6 & 82.718 .564 & 16.543 .712 & 135,8 & 31,7 \\
\hline $1890 \ldots \ldots$ & 53.801 .591 & 94,5 & 86.425 .582 & 17.285 .116 & 141,9 & 32,1 \\
\hline $1891 \ldots \ldots \ldots$ & 61.714 .395 & 108,5 & 103.724 .882 & 20.744 .976 & 170,3 & 33,6 \\
\hline $1892 \ldots$ & 77.931 .671 & 136,9 & 115.004 .727 & 23.000 .945 & 188,9 & 29,5 \\
\hline $1893 \ldots$ & 78.706 .506 & 138,3 & 121.758 .941 & 24.351 .785 & 200,0 & 30,9 \\
\hline $1894 \ldots .$. & 75.678 .261 & 133,0 & 117.061 .881 & 23.412 .376 & 192,2 & 30,9 \\
\hline $1895 \ldots \ldots \ldots$ & 52.871 .259 & 92,9 & 119.344 .000 & 23.868 .800 & 196,0 & 45,1 \\
\hline $1896 \ldots \ldots \ldots$ & 40.017 .730 & 70,3 & 134.461 .000 & 26.892 .200 & 220,8 & 67,2 \\
\hline $1897 \ldots \ldots \ldots$ & 18.406 .815 & 32,3 & 123.424 .384 & 24.684 .876 & 202,7 & 134,1 \\
\hline $1898 \ldots \ldots \ldots \ldots$ & 15.236 .477 & 26,8 & 67.441 .000 & 13.488 .200 & 110,7 & 88,5 \\
\hline
\end{tabular}

FUENTES:

(1) Moreno Fraginals (1987), III, 85.

(2) Dirección General de Aduanas, Estadística general del Comercio exterior, 1877-1898. Se han deducido las remesas de oro y plata.

(3) Valor basado en una conversión de cinco pesetas por dólar (pese a la depreciación de la peseta respecto al patrón oro, se mantuvo la equivalencia entre el duro y el peso cubano y la paridad dólar/peso). 


\section{GRÁFICO 3}

Compensación de las exportaciones

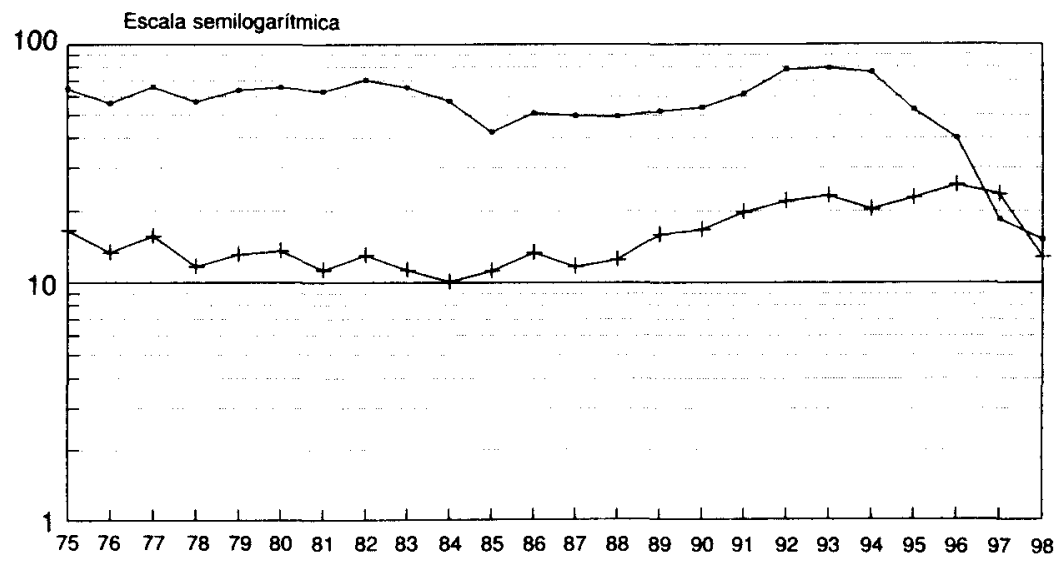

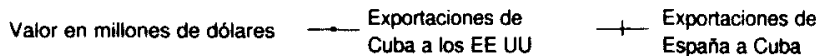

Podemos concluir que la mejora de las exportaciones cubanas conseguida en 1891 favoreció la importación de artículos peninsulares en la misma medida que crecieron aquéllas, pero no mucho más pese a la protección arancelaria reforzada un año después. En términos absolutos el superávit de la balanza cubana con el vecino continental preferentemente se dirigió a la adquisición de bienes en los Estados Unidos, coincidiendo con la fuerte reducción del comercio cubano-británico, del que los norteamericanos fueron sus principales beneficiarios. La pérdida de presencia del Reino Unido en el comercio exterior cubano, de otra parte, sería explicable menos por la reciprocidad mercantil acordada con los norteamericanos en 1891 — según suele argumentarse - como por la caída de las importaciones de azúcar para la industria británica que modificó los cauces mercantiles establecidos. En el mismo sentido, los Estados Unidos se hallaron en condiciones inmejorables para rentabilizar el transporte empleado en la importación de azúcares redondeando el viaje. De hecho, como consecuencia del Tratado de 1891 la prensa cubana optó por hablar de un doble monopolio, el peninsular y el estadounidense, que 
creyó amenazado por los tratados de comercio suscritos por España con países europeos, en los que éstos buscaban extender los beneficios de nación más favorecida a las colonias ${ }^{20}$.

\section{ANÁLISIS DEL INTERCAMBIO: CONTENIDO Y SUERTE DE LAS EXPORTACIONES ESPAÑOLAS}

El examen concreto de las exportaciones peninsulares a Cuba desde el Zanjón al comienzo de la guerra de 1895 - fecha a partir de la cual se distorsiona la balanza - ofrece una serie de cambios que han sido ya señalados por diferentes autores. Podemos resumirlos en la sustitución de productos agrícolas que en 1880-84 representan más de dos tercios del total, por artículos manufacturados que ganan posiciones y se sitúan finalmente en cabeza, llegando a suponer más del 60 por 100 de las importaciones cubanas de procedencia española en el quinquenio 1890-94 (cuadro 4).

Nos detendremos en las características del intercambio, un aspecto que nos parece menos atendido y que viene oscurecido por la publicística de la época y, a partir de ésta, por una historiografía que no ha contrastado empíricamente los argumentos interesados de aquélla.

Además de disponer de un régimen arancelario favorable ${ }^{21}$, las exportaciones españolas respondieron a un conjunto de circunstancias que aparecen subrayadas una vez ese régimen comience a modificarse en 1891-92 en aplicación del Tratado con los Estados Unidos, con exenciones y rebajas tarifarias ${ }^{22}$. Tras la entrada en vigor del acuerdo comercial no

${ }^{20}$ "Los tratados de comercio», en Diario de la Marina, 30 de mayo de 1893.

${ }^{21}$ El diferencial a favor de España tendió a mantenerse pese a las rebajas arancelarias aplicadas a otras naciones gracias a los recargos introducidos en las tarifas en los presupuestos anuales de la Isla de Cuba. Véase Labra (1901), p. 100. Sin embargo se carece de estudios empíricos sobre la repercusión efectiva del régimen fiscal y arancelario que pesaba en las mercancías introducidas en la colonia.

${ }^{22}$ El Tratado de comercio entre España y Estados Unidos de 1891 establecía una lista transitoria cuyos efectos comenzaron a regir el 1 de septiembre de 1991 (excepto harina y trigo, que se posponía a 1 de enero de 1892) y una lista definitiva a partir del 1 de junio de 1892. La lista transitoria comprendía en primer lugar productos norteamericanos cuya importación en adelante quedaba libre de derechos en Cuba: carne en conserva, tocino, jamones y derivados cámicos, manteca de cerdo y grasas animales, pescado enlatado, semillas y aceite de semilla de algodón, maderas, legumbres y bortalizas verdes y secas, etc. Las harinas y el trigo bajaban su arancel. Se reducía también en un 25 por 100 (respecto al arancel de la tercera columna: productos extranjeros en buques extranjeros) el calzado de cuero $y$ piel. La lista definitiva se dividía en cuatro grupos, según la rebaja de aranceles que 


\section{CUADRO 4}

Composición de las exportaciones españolas a Cuba (expresión en porcentajes)

\begin{tabular}{|c|c|c|c|}
\hline & $1880-84$ & $1885-89$ & $1890-94$ \\
\hline \multicolumn{4}{|l|}{ ALIMENTOS } \\
\hline 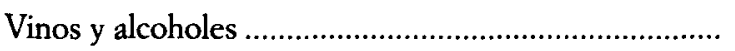 & 27,23 & 21,11 & 9,31 \\
\hline 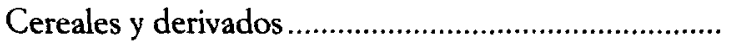 & 15,60 & 10,01 & 6,51 \\
\hline 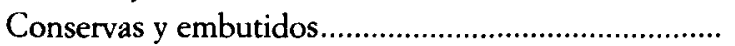 & 5,22 & 4,80 & 5,49 \\
\hline 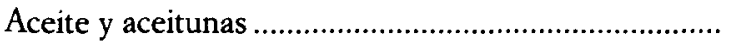 & 5,42 & 6,53 & 4,91 \\
\hline Legumbres y productos hortícolas y frutos secos........ & 3,76 & 3,73 & 3,54 \\
\hline \multirow[t]{2}{*}{ Varios } & 0,79 & 2,16 & 3,07 \\
\hline & 58,02 & 48,34 & 32,83 \\
\hline \multicolumn{4}{|l|}{ MANUFACTURAS } \\
\hline Textiles ...................... & 5,56 & 13,09 & 24,54 \\
\hline Calzado........ & 12,88 & 16,94 & 17,76 \\
\hline Papel, sacos y cordelería, y pipería ............................. & 1,72 & 4,63 & 7,92 \\
\hline 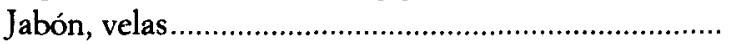 & 4,93 & 6,27 & 5,16 \\
\hline Abanicos, sombreros, paraguas y sombrillas ............... & 0,65 & 1,31 & 1,23 \\
\hline \multirow[t]{2}{*}{ Varios } & 1,98 & 1,96 & 3,64 \\
\hline & 27,72 & 44,20 & 60,25 \\
\hline TOTAL REGISTRADO ......... & 85,74 & 92,54 & 93,08 \\
\hline
\end{tabular}

FuENTE: Dirección General de Aduanas, Estadística general del Comercio exterior, 18801894. Excluidas las remesas de moneda.

se alteró la demanda de determinados artículos de procedencia peninsular, pues los productos beneficiados por la nueva situación pasaron de representar aproximadamente el 40 por 100 de los valores importados de España en 1885-89 a suponer el 38 por 100 en el quinquenio 1890-94,

experimentaban: la tabla A comprendía artículos libres de derechos (carbón mineral, petróleo bruto, hierro fundido y forjado, acero, etc.). La tabla $\mathrm{B}$ incorporaba los productos de la lista transitoria sujetos a gravámenes especiales. La tabla $\mathrm{C}$ disfrutaba de una rebaja del 50 por 100 sobre aranceles vigentes: hojalata, arroz y pastas alimenticias figuraban en este apartado. La tabla D rebajaba un 25 por 100 las jarcias, jabones, papel para imprimir, etc. (en cursiva los artículos comprendidos entre las veinte primeras importaciones de productos peninsulares). Las reducciones quedaron matizadas por la modificación arancelaria de 1892 que se tomaría de base para calcularlas. 
cuando el volúmen global de importaciones se había incrementado el 62 por $100^{23}$.

Entre las circunstancias que favorecieron las exportaciones españolas en las dos últimas décadas del XIX, señalemos las siguientes:

a) La depreciación de la peseta respecto al patrón oro desde inicios de los años 1880 y sobre todo a partir de 1889 mejoró la posición del mercado cubano, que cobraba sus exportaciones en dólares, una moneda que se había reforzado frente a la española. El peso/oro mantuvo la paridad oficial con el duro español pero los premios de que gozó la moneda cubana en el cambio permitieron que se trasladara a los pagos la diferencia de valor monetaria. En 1883 se abandonaría la convertibilidad en oro de los billetes españoles mientras se mantuvo en Ultramar la de los billetes del Banco Español de la Isla de Cuba, bien es verdad que con descuentos. El patrón plata adoptado de hecho en la Península vino a coincidir en los años ochenta, como es sabido, con la baja de este metal, de modo que las acuñaciones experimentaron una sensible depreciación de hasta el 25 por 100 en 1886. En suma, las importaciones peninsulares comenzaron a gozar de un margen de competitividad adicional proporcionado por la evolución del valor de la peseta y el diferencial de valor del peso/oro equivalente al dólar en que se percibían en Cuba los ingresos de la balanza exportadora.

b) Las exportaciones españolas corresponden en buena parte a productos alimentarios de consumo popular, cuya demanda bien pudo estar incentivada por la notable inmigración española registrada durante los últimos lustros de dominio colonial; una inmigración golondrina en muchos $\operatorname{casos}^{24}$, de origen rural, propiciada por la crisis agraria peninsular ${ }^{25}$, lo que explicaría el aumento en la importación de ciertos artículos habituales en la dieta popular española (legumbres, frutos hortícolas, grasas animales, etc.). Las legumbres, incluidas en la tabla transitoria de inmediata aplicación en el Tratado de 1891 para las procedentes de los Estados Unidos, no siguieron, por ejemplo, la suerte de las harinas y después de esa fecha mantuvieron su importancia en el comercio hispano-colonial. Esos mismos productos pasaron a formar parte de la tradición alimentaria criolla.

c) Un volumen estimable de las transacciones consistió en productos alimentarios tradicionales: vino común, generosos, aguardientes y jerez,

${ }^{23}$ Véase anexo 1 para seguir la evolución de las veinte primeras partidas exportadoras españolas a Cuba.

${ }^{24}$ Características y cuantificación en Naranjo (1992).

${ }^{25}$ Robledo (1988). 
aceite, aceitunas, pasta, conservas, arroz, etc., con mercados estables en el exterior, tanto en América como en Europa. Los aranceles incidirían poco en su introducción. Piénsese que en la década de 1880 , como ya sucediera en 1860 , los vinos españoles reemplazaron a los caldos franceses afectados por la filoxera ${ }^{26}$. El jerez tenía en Inglaterra su destino preferente. El aceite español se exportaba a Europa con fines industriales, pero tenía en América Latina un mercado orientado al consumo alimentario, además de utilizarse como lubricante ${ }^{27}$. Las importaciones de pastas para sopa, conservas y arroz procedentes de España no dejaron de crecer después del Tratado con los Estados Unidos de 1891, a pesar de la rebaja arancelaria del 50 por 100 reconocida en esos mismos artículos de procedencia norteamericana. La industria conservera española se desarrolló precisamente a partir de los años ochenta, por lo común a partir de pescado enlatado, en aceite o escabechado, además de salazones; América Latina constituía el primer mercado exterior, con México a la cabeza, siendo apreciables también las exportaciones a Francia y Alemania ${ }^{28}$. Las variaciones que experimentaron los productos reunidos en este apartado -cuyos valores oscilaron entre el 45 por $100(1880-84)$ y el 28 por 100 (1890-94) del total de las importaciones- debieron obedecer a causas ajenas al régimen arancelario.

d) Las principales manufacturas exportadas (calzado, tejidos, jabón, etc.) eran productos destinados a sectores populares, con precios inferiores a los norteamericanos, también de calidad inferior, orientados al gusto local, y que siguen favorecidos por el arancel pese a la rebaja del 25 por 100 en 1891. Llegaron a competir con otras importaciones hasta motivar un

${ }^{26}$ Los vinos españoles conservaron los mercados americanos después de reemplazar a los franceses en la década de 1860 . Como es conocido, el vino constituyó durante el siglo xx el principal capitulo exportador español y en las dos.últimas décadas del siglo el 80 por 100 se dirigió al mercado francés, siguiéndole en importancia los países del Río de la Plata - de donde una parte se reexportaba a Brasil-y las Antillas españolas. Véase Piqueras (1985), pp. 78-81 y 232-233.

${ }^{27}$ Los aceites españoles, en particular los del área mediterránea con un valor similar a los andaluces pero de mayor calidad, disputaban a los italianos el mercado sudamericano al final del siglo (Nadal, 1987, p. 30); un 25 por 100 de la exportación se dirige a Italia para refinar y envasar con destino a América (Zambrana, 1985, p. 302).

${ }^{28}$ Ortega Valcárcel (1990), pp. 82 y 98-99; Carmona Badía (1990), p. 36; Nadal (1987), pp. 32-34. La industria de conservas vegetales alcanzó también un cierto desarrollo en la Península, con mercado en Europa y atracción de capitales extranjeros: Martínez Carrión (1989). 
descenso en los precios de aquéllas ${ }^{29}$. Eran «artículos todos que consumen las clases menesterosas» ${ }^{30}$. Y continuaron compitiendo cuando la Isla dejó de ser una colonia. Al respecto, Alejandro García se ha hecho eco de la preocupación norteamericana, en 1906, por la presencia en el mercado cubano de ciertos productos de procedencia española: textiles y calzado de cuero ${ }^{31}$.

e) Los fletes de los buques españoles eran cada vez más competitivos, interesados como estaban en captar carga en la Península para redondear viajes. Disponían además de inversiones amortizadas en infraestructura portuaria (muelles, almacenes, etc.). Durante la primera década de la futura República los navíos españoles entrados en La Habana llegarán a superar en tonelaje bruto a los de bandera norteamericana y a ofrecer fletes a Europa más bajos que los vigentes entre Nueva York y el Caribe, llevando ventaja, en suma, en el tráfico comercial ${ }^{32}$.

Los productos de consumo popular, entre agrícolas y manufacturados (vino común, calzado, tejidos, conservas, manteca, jabón, etc.) representaron por encima del 50 por 100 del valor de las exportaciones peninsulares a Cuba, siendo además el apartado que más creció, hasta suponer el 60 por 100 de aquéllas en vísperas de la guerra del 95. Los alimentos generales (aceite, legumbres, frutos secos, embutidos, chocolate, etc.) vinieron a situarse en el 10-13 por 100. Algunas manufacturas suntuarias (abanicos, encajes de hilo) tenían también un mercado propio, pero no aportaban más del 2 por 100 del valor de las mercancías. Las manufacturas para uso comercial e industrial (papel, pipería, sacos) podían representar el 5-8 por 100. Las harinas, en declive desde 1881, sufrieron una importante caída en cuanto perdieron el arancel prohibicionista (trigo, harina y derivados pasaron del 15 al 6 por 100), pero esto sucedió a la vez que se hundía el precio internacional del trigo, lo que desincentivó la reexportación de harinas extranjeras a Cuba al desequilibrar la relación

29 Recuérdese las características del calzado procedente de Mallorca. La elaboración de jabón con aceite de oliva se vio favorecida por los aranceles a la importación de aceites de semillas oleaginosas vigentes en España y el bajo precio alcanzado por el orujo en las dos últimas décadas del siglo XXX (Zambrana, 1985, p. 305).

${ }^{30}$ Alzola (1895), p. 112. Según cita el autor, el Informe sobre aranceles antillanos del Fomento del Trabajo Nacional de Barcelona destacaba ese destinatario y señalaba cómo la aparición de productos peninsulares similares a los importados del extranjero (calzado, confecciones y jabón) había llevado a que éstos bajasen sus precios. p. 84

${ }^{31}$ C. Pepper: Report of Trading Conditions in Cuba. 1906, cit. por García Álvarez (1990),

32 Garcia Álvarez (1990), pp. 85-86. 
valor/fletes, y redujo el impacto de la protección arancelaria cualquiera que fuera.

\section{MERCADOS CAUTIVOS, CONSUMO DESIGUAL, CAPTURA DEL ESTADO}

La dependencia colonial y la política arancelaria discriminatoria practicada por la Metrópoli en la Isla son hechos estrechamente relacionados y entran dentro de la lógica de la explotación colonial destinada a garantizar la acumulación y reproducción de capitales en condiciones privilegiadas. Era perfectamente coherente que la burguesía metropolitana desoyera las protestas originadas en sus posesiones, como lo era que los autonomistas cubanos y unas u otras corporaciones económicas, según qué circunstancias, elevaran sus voces a fin de presionar al gobierno español en favor del comercio antillano. Sin embargo conviene distinguir entre la disputa del beneficio por la burguesía comercial cubana y una pretensión de más largo alcance, la demanda de una determinada política comercial exterior que favoreciera las exportaciones de azúcar hacia los Estados Unidos, lo que en la época de los grandes tratados comerciales implicaba necesariamente ajustar medidas de reciprocidad en las que estaban interesados tanto los norteamericanos como el sector mercantil insular relacionado con las importaciones de aquel país, amén de hacendados azucareros y el sector tabaquero ${ }^{33}$.

La reciprocidad arancelaria era una condición del comercio bilateral reconocida por diferentes sectores de la economía cubana, y su ausencia se percibe como una amenaza para los intereses exportadores que Estados Unidos convierte en realidad con el bill McKinley de 1890 que cierra el mercado norteamericano al azúcar cubano. El Movimiento Económico forzó la negociación en favor de lo que sería un año después el Tratado

${ }^{33} \mathrm{El}$ «Manifiesto al País» con motivo de la fundación del partido Liberal, el 3 de agosto de 1879, solicitaba, entre otros, la suspensión de los derechos de importación que pudieran considerarse diferenciales o protectores, «requisito necesario para celebrar tratados de comercio que nos proporcionen mercados ventajosos para nuestras producciones»; el programa económico del nuevo partido reclamaba «Tratados de comercio entre España y las naciones extranjeras, particularmente con Estados Unidos, sobre la base de la más completa reciprocidad arancelaria entre aquéllas y Cuba». El programa fundacional de la Unión Constitucional, el 20 de noviembre de 1878, reclamaba la celebración de tratados, «en particular con Estados Unidos, mercado principal de estos frutos, sobre bases de amplia reciprocidad». Cit. en Estévez Romero (1974), I, pp. 55, 57 y 74. La Junta Magna convocada en 1884 se pronunció asimismo por facilitar las relaciones comerciales con Estados Unidos. 
Foster-Cánovas. Al quedar fuera, los tabaqueros buscaron la libre venta en España, mientras la reacción antiarancelaria quedó en manos de la Cámara de Comercio, la Liga de Comerciantes Importadores y sectores mercantiles no vinculados ni a la Península ni a Estados Unidos, o relacionados con la débil industria local. Los aranceles protectores de 1892 les dieron nuevos motivos de protesta al acentuar el contenido de las Leyes de Relaciones de 1882.

A finales de la década de 1880 prácticamente todos los sectores productivos, exportadores e importadores de mercancías no peninsulares -y desde 1891 los excluidos del convenio-, forjaron una red de intereses que para lograr sus objetivos no dudó en recurrir a la opinión pública -que irrumpe en Cuba como factor ineludible después del Zanjóncultivando dos tipos de argumentos: las trabas que la Metrópoli oponía al desarrollo económico de la Isla y la política fiscal y comercial impuesta por España, que expoliaba las arcas insulares — preferentemente para atender la Deuda - y condenaba a su población a consumir bienes de dudosa calidad a precios excesivos. Eran argumentos, de otra parte, de secular y eficaz resonancia anticolonial, por más que ésta no fuera la pretensión de la mayoría de quienes los emplearon. Intercambios comerciales, opinión pública y nacionalismo viajaron en el mismo convoy aunque con destinos diferentes.

Ahora bien, en el período comprendido entre 1880 y el inicio de la guerra de 1895 , España suministraba en torno al $30-35$ por 100 de las importaciones de la Isla. Después de entrar en vigor el Tratado con los Estados Unidos las importaciones legales procedentes de este país crecieron con rapidez y en 1894 superaban a las de procedencia peninsular ${ }^{34}$ (cuadro 5).

34 No podemos compartir el cálculo de Maluquer (1974), p. 351, que presenta conjuntamente los porcentajes de 1894 y 1895 , lo que lleva a que España acapare el 43,1 por 100 del mercado insular mientras Estados Unidos se sitúa en el 37,4 por 100 . El autor se basa en la Estadistica general del comercio exterior de la Isla de Cuba de 1894 y 1895, única oficial, que presenta a los Estados Unidos como el primer proveedor en 1894 (32,5 millones de pesos), seguido de España (30,6 millones) e Inglaterra (5,6 millones), distribuyéndose el resto (15,5 millones) entre otros países. España tendría una cuota de mercado del 36,3 por 100 y los Estados Unidos del 38,6 por 100. La omisión de la secuencia que comienza en 1891 de la tabla de Alzola que reproducimos deja en la penumbra que Estados Unidos había alcanzado el predominio mercantil. Respecto a la información sobre 1895 hay que indicar que está condicionada por la suspensión del Tratado de 1891 al entrar en vigor el arancel Wilson y por el comienzo de la guerra.

Zanetti (1975), pese a calificar la posición española de monopólica, reconoce que durante todo el siglo XIX «las importaciones se mantenían relativamente diversificadas, repartiéndose 


\section{CUADRO 5 \\ Comercio de importación de Cuba. Principales proveedores \\ (valor en miles de pesos)}

\begin{tabular}{|c|c|c|c|c|}
\hline & 1891 & 1892 & 1893 & 1894 \\
\hline 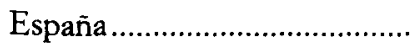 & 20.745 & 23.001 & 24.402 & 30.620 \\
\hline 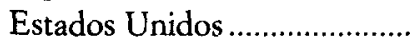 & 12.225 & 17.954 & 24.158 & 32.948 \\
\hline
\end{tabular}

FUENTE: 1891-1893: Alzola (1895), p. 167, según Estadísticas comerciales de los respectivos países; 1894: Directorio de La Habana y Guia comercial de Cuba, Nueva York (1899), cit. por Roig de Leuchsenrin (1949), p. 154.

Se asiste a la disputa de un mercado en patente crecimiento desde 1891 en el que los restantes países pierden peso específico en conjunto al pasar de unos 18 millones de pesos en aquella fecha a 21 millones desde 1892.

Significa que Cuba estuvo surtiéndose en terceros países de la mayor parte de cuanto consumía a lo largo de la etapa estudiada: entre el 70 y el 65 por 100 por término medio. Del mismo modo que el derecho diferencial de bandera encareció las importaciones mientras estuvo vigente pero no impidió que la mayor parte de éstas se hicieran en buques extranjeros, los aranceles protectores contribuyeron a la carestía en la Isla pero ni siquiera en época de depresión de los precios del azúcar lograron acotar en exclusiva el mercado cubano para los artículos peninsulares. Es muy posible además que las cifras oficiales que sitúan a la Península en el primer orden de abastecedores fueran en la práctica corregidas gracias al próspero contrabando que se desarrolla entre los Estados Unidos y la Isla: «El comercio de buena fe está arruinado en Cuba», anota un observador en 1886 haciéndose eco de la opinión de los comerciantes españoles instalados en La Habana; si el comentario - sin duda interesado- resulta una exageración, la matización que le sigue no se aleja de la realidad: «La propensión a ejercer el contrabando está allí muy

más o menos proporcionalmente entre España, Estados Unidos, Inglaterra y otros paises» (p. 97). A la vez considera que se mantuvieron «ampliamente repartidas» hasta la firma del Tratado de Reciprocidad de 1903 con los Estados Unidos, pese a que desde 1899 éstos acaparaban el 43 por 100 del mercado cubano (p. 104), una cifra que jamás había alcanzado España en tiempos de paz. Las pautas económicas posteriores a la independencia, clarificadas asimismo por Zanetti (1989), no parece que puedan retrotraerse al período colonial sustituyendo una potencia extranjera por otra. 
desarrollada. Al contrabando negrero ha sucedido el de los artículos importados» ${ }^{35}$.

El encarecimiento de la vida en Cuba en la segunda mitad de los ochenta vino motivado por el nivel de precios de los artículos importados (españoles, norteamericanos o de terceros países) respecto al descenso de los ingresos, además de obedecer a prácticas especulativas. La posición española como proveedora de productos destinados al consumo popular atrajo la atención de la crítica interesada en denunciar una situación de la que esperaban conseguir compensaciones. Después de todo, en lo tocante a los artículos alimenticios, que eran los de mayor incidencia en la determinación de la carestía, las exportaciones efectuadas desde España venían perdiendo peso específico y valor neto en favor de otros países, como vimos en el cuadro 4.

Sin duda hubo casos excepcionales dentro del cuadro descrito. Primero las harinas, más tarde los artículos textiles. En el momento de máximo auge en la importación de algodón y manufacturas de algodón de origen peninsular, en el primer trimestre de 1894 representaron el 64,3 por 100 de las importaciones textiles en Cuba: una cifra muy estimable, sin duda, pero para tratarse de una manufactura especialmente protegida por el arancel dejaba una considerable cuota de mercado en manos de otros proveedores, al margen de los precios que éstas pudieran alcanzar, que es otra cuestión ${ }^{36}$. La información disponible corrobora la diversidad de procedencias. Además de las estadísticas fiscales contamos con testimonios complementarios: desde la publicidad contemplada en la prensa habanera y los directorios comerciales, a los registros de entrada de buques extranjeros o los inventarios levantados en los expedientes de quiebra de

${ }^{35}$ Peris Mencheta (1993), p. 246.

36 «Prueba que ni aun en los ramos de mayor progreso se ha acaparado el mercado cubano, representando las introducciones exóticas en tejidos de algodón el 35,7 por 100 declarado oficialmente, y como el fraude se refiere precisamente a los géneros gravados con derechos, es probable alcance y supere el total de importación extranjera efectiva a la peninsular», afirma Alzola (1895), pp. 180-181. En el mismo trimestre, las importaciones de tejidos de algodón de los Estados Unidos representaban el 6,57 por 100 -cifra totalmente improbable - y eran de otras procedencias el 29,13 por 100. Los artículos siderúrgicos importados de los Estados Unidos suponían el 79,7 por 100 del valor del conjunto de aquellas importaciones.

Los juicios de Pablo de Alzola, orientados por su condición de comisionado de los fabricantes peninsulares (Liga Nacional de Productores) e impregnados de un cariz colonialista, no invalidan la labor estadística de un trabajo basado en fuentes oficiales, por más que algún cuadro concreto deba ser tomado con cautela. 
establecimientos mercantiles ${ }^{37}$, una línea de investigación que de practicarse sistemáticamente ofrecería, sin duda, un mejor conocimiento de la estructura comercial de la Isla ${ }^{38}$.

Si tenemos presente el fenómeno del contrabando, ya indicado, y deducimos vino, aceite y otros productos alimentarios cuya demanda no es atribuible al arancel protector, equé queda? La gran mayoría de los bienes consumidos en Cuba era, las evidencias parecen concluyentes, de procedencia extranjera pese a la reiterada denuncia sobre la obligación de adquirir mercancías peninsulares a que estaba sometida la Isla.

En mi opinión, periodistas, publicistas, representantes cualificados de las asociaciones económicas creadas en los años 1870 y 1880 y sectores manifiestamente políticos, en particular los autonomistas, cuyo sentido nacional fue in crescendo aunque no tanto como para comprender que pudiera ser incompatible con la pertenencia a España, generaron un discurso destinado a presionar sobre el gobierno español para obtener un objetivo específico: la negociación de un tratado con los norteamericanos que diera satisfacción a las exigencias de reciprocidad mercantil y con ello posibilitara la libre exportación de productos cubanos - azúcar, claro estáa Estados Unidos. De suerte que el discurso de la cautividad mercantil aparece, incluso después de la entrada en vigor de las Leyes de Relaciones Comerciales - un auténtico fraude a la reciprocidad hispano-colonial-, con un carácter más instrumental que descriptivo.

El discurso, en cambio, surtió efecto entre las clases populares, para las que en mayor medida correspondía a su realidad concreta. Porque a partir de una mínima capacidad adquisitiva, los individuos se podrán ver impelidos a renunciar a un conjunto de bienes específicos pero no podrán prescindir de otros básicos. En suma, la cuestión no será tanto el menor consumo de bienes fundamentales como la adquisición de bienes de menor precio $\mathrm{y}$, por lo común, de calidad inferior. $\mathrm{Y}$ ese mercado popular, ampliado en la década de 1880 con los emancipados de la esclavitud y los inmigrantes españoles, era al que se dirigía preferentemente la producción peninsular.

37 A modo indicativo, el estado de cuentas levantado con motivo de la quiebra de una importante ferretería de La Habana en 1861, «Carbajosa, Ibarzal y Cía.», que presentaba un balance de 578.037 pesos, permite establecer el orden de proveedores: Estados Unidos, Inglaterra, Francia y, por último, España, en un sector supuestamente al servicio de los ferrateros vascos. Archivo Nacional de Cuba, Tribunal de Comercio, leg. 135, núm. 4.

${ }^{38}$ Sobre la estructura comercial de la etapa final de la colonia y primeras décadas de la República, la doble condición de importador/exportador de los comerciantes y la especialización en artículos más que en la procedencia de éstos, caracterizada por la diversidad, García Álvarez (1990), pp. 33-53. 
La retórica victimista, practicada —en estricto sentido gramscianopor los intelectuales orgánicos de la burguesía insular y orientada a mejorar las condiciones en que ésta desenvolvía su economía, fue impregnando la sociedad cubana de arriba a abajo y propició lecturas socialmente convergentes pese a la diversa repercusión de la estructura comercial descrita en las diferentes clases sociales.

Quienes generaron el discurso y, muy probable, quienes lo difundieron pertenecían a estratos cuya capacidad económica les permitía acceder a artículos de mayor calidad y más elevado precio, importados en gran medida de los Estados Unidos o del Reino Unido en los años ochenta. Pero fueron capaces de elaborar un mensaje que implicaba la idea del interés general por encima del provecho particular de clase al presentar el mercado cubano como una entidad global, preso del abuso y la inmoderada avidez de la Metrópoli. Consiguieron oscurecer la realidad de un consumo desigual en función de la desigual fortuna, y lo hicieron de tal forma que la historiografía de la futura república incorporó esa visión a la interpretación del período. Supieron, en definitiva, proyectar esa «ilusión heroica» indispensable en el proceso de emergencia de una burguesía nacional, aunque la razón meramente instrumental que movió a ello acabaría dejando en manos de las capas medias el liderazgo del proyecto emancipatorio que condujo a la insurrección de 1895. 


\section{ANEXO 1}

Composición de las exportaciones españolas a Cuba. Veinte mayores productos. Valores totales quinquenales Años 1880-1884

\begin{tabular}{|c|c|c|c|}
\hline Producto & Valor pesetas & Porcentaje & \\
\hline 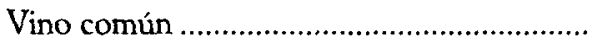 & 69.251 .676 & 22,44 & \\
\hline Harina de trigo, trigo y pasta ....................... & 46.810 .601 & 15,17 & \\
\hline 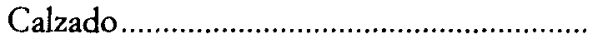 & 36.673 .230 & 11,88 & \\
\hline $\begin{array}{l}\text { Otros alcoholes (aguardientes, generoso, } \\
\text { anisados, jerez) }\end{array}$ & 14.798 .696 & $4,79^{*}$ & \\
\hline 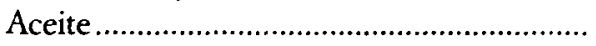 & 14.630 .841 & 4,74 & \\
\hline Conservas alimentarias ................................... & 13.621 .027 & 4,41 & \\
\hline Algodón y sus manufacturas.......................... & 13.332 .471 & $4,32 *$ & \\
\hline 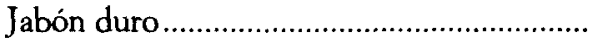 & 11.302 .729 & 3,66 & \\
\hline 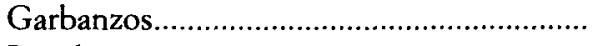 & 8.129 .938 & 2,63 & \\
\hline 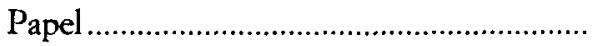 & 4.386 .263 & 1,42 * & \\
\hline 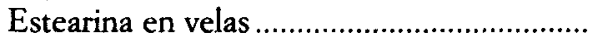 & 3.939 .688 & 1,27 & \\
\hline 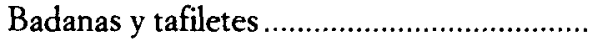 & 3.206 .418 & 1,04 & \\
\hline 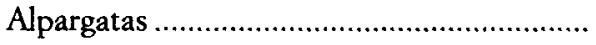 & 3.097 .446 & 1,00 & \\
\hline Embutido............................. & 2.511 .796 & 0,81 & \\
\hline 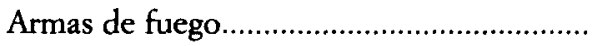 & 2.149 .620 & 0,70 & \\
\hline 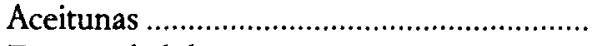 & 2.109 .969 & 0,68 & \\
\hline 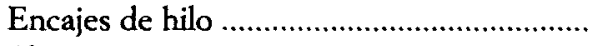 & 2.070 .655 & 0,67 & \\
\hline 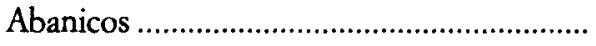 & 2.000 .825 & 0,65 & \\
\hline Tejidos de cáñamo y lino............................... & 1.763 .728 & 0,57 & \\
\hline 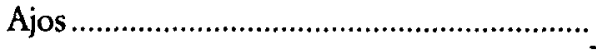 & 1.712 .662 & $0,55 *$ & $(83,4)$ \\
\hline TOTAL EXPORTACIONES ............ & 308.607 .164 & 100,00 & \\
\hline
\end{tabular}


Años 1885-1889

\begin{tabular}{|c|c|c|c|}
\hline Producto & Valor pesetas & Porcentaje & \\
\hline Vino común o de pasto & 66.894 .158 & 19,90 & \\
\hline 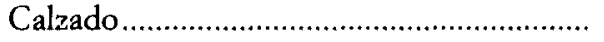 & 53.859 .300 & 16,03 & \\
\hline Algodón y sus manufacturas............................... & 38.816 .802 & $11,55 *$ & \\
\hline Harina de trigo, trigo y pasta ........................... & 32.272 .571 & 9,60 & \\
\hline Aceite & 18.621 .978 & 5,54 & \\
\hline Jabón duro & 15.270 .044 & 4,54 & \\
\hline 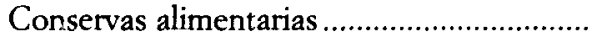 & 12.311 .451 & 3,66 & \\
\hline 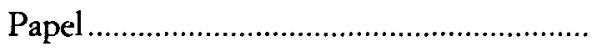 & 7.211 .526 & 2,14 * & \\
\hline 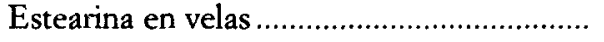 & 5.821 .385 & 1,73 & \\
\hline 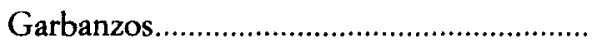 & 5.304 .794 & 1,58 & \\
\hline 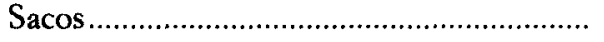 & 4.851 .604 & 1,44 & \\
\hline Ajos & 4.159 .270 & 1,24 & \\
\hline $\begin{array}{l}\text { Otros alcoholes (aguardientes, generoso, } \\
\text { anisados, jerez)... }\end{array}$ & 4.082 .921 & 1,21 & \\
\hline Badanas y tafiletes & 3.968 .724 & 1,18 & \\
\hline Embutido & 3.823 .175 & 1,14 & \\
\hline Abanicos & 3.812 .450 & 1,13 & \\
\hline Encajes de hilo .............................................. & 3.759 .800 & 1,12 & \\
\hline 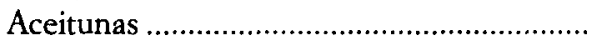 & 3.332 .337 & 0,99 & \\
\hline Alpargatas & 3.075 .180 & 0,91 & \\
\hline Pipería...... & 2.553 .635 & 0,76 & $(87,39)$ \\
\hline TOTAL EXPORTACIONES .............. & 336.069 .393 & 100,00 & \\
\hline
\end{tabular}

Años 1890-1894

\begin{tabular}{|c|c|c|}
\hline Producto & Valor pesetas & Porcentaje \\
\hline Algodón y sus manufacturas... & 106.231 .153 & 19,53 \\
\hline 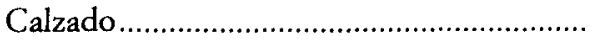 & 94.266 .304 & 17,33 \\
\hline Vino común o de pasto & 50.622 .488 & 9,31 \\
\hline Harina de trigo, trigo y pasta & 29.823 .134 & 5,48 \\
\hline 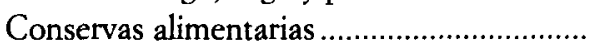 & 22.616 .183 & 4,16 \\
\hline Aceite & 21.652 .537 & 3,98 \\
\hline 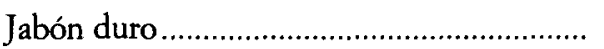 & 18.558 .024 & 3,41 \\
\hline Pipería & 14.875 .828 & 2,73 \\
\hline Papel & 14.764 .896 & 2,71 \\
\hline 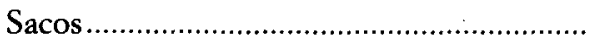 & 11.753 .511 & 2,16 \\
\hline
\end{tabular}




\begin{tabular}{|c|c|c|c|}
\hline Producto & Valor pesetas & Porcentaje & \\
\hline 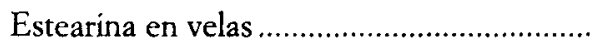 & 9.531 .105 & 1,75 & \\
\hline 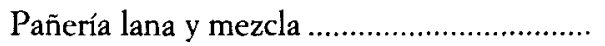 & 39.312 .046 & 1,71 & \\
\hline 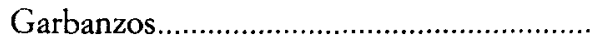 & 8.575 .029 & 1,58 & \\
\hline Tejidos de cáñamo y lino............................... & 7.519 .086 & 1,38 & \\
\hline 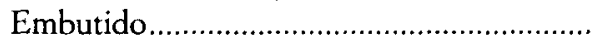 & 7.237 .220 & 1,33 & \\
\hline 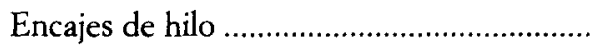 & 6.519 .260 & 1,20 & \\
\hline Arroz ...................... & 5.618 .735 & 1,03 & \\
\hline 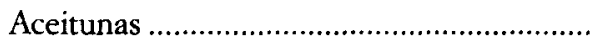 & 5.070 .744 & 0,93 & \\
\hline 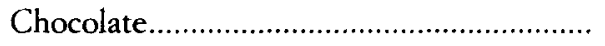 & 4.871 .166 & 0,90 & \\
\hline 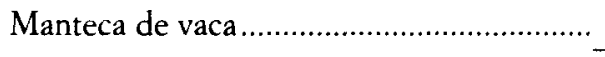 & 4.105 .398 & 0,75 & $(83,36)$ \\
\hline TOTAL EXPORTACIONES ............. & 543.976 .013 & 100,00 & \\
\hline
\end{tabular}

FUENTE: Dirección General de Aduanas, Estadística general del Comercio exterior, 18801894. Porcentaje sobre mercancías, excluidas remesas de moneda.

* No se han contabilizado algunas partidas en los años en que representan escaso valor.

\section{BIBLIOGRAFÍA}

Alzola y Minondo, Pablo de (1895): Relaciones comerciales entre la Península y las Antillas, Madrid, Impr. Vda. Minuesa de los Ríos.

Bahamonde, Ángel, y Cayuela, José (1992): Hacer las Américas. Las élites coloniales españolas en el siglo XIX, Madrid, Alianza.

Carmona BadiA, Xoán (1990): «Crisis y transformación de la base industrial gallega, 1850-1936)», en NADAL, J. y Carreras, A. (dir.), Pautas regionales de la industrialización española (siglos XIX y XX), Barcelona, Ariel, pp. 23-48.

Dirección General de Aduanas (1860-1898): Estadistica General del Comercio Exterior, Madrid.

EstÉvez Romero, Luis (1974): Desde el Zanjón basta Baire (1. ${ }^{2}$ ed. en 1899), La Habana, Editorial de Ciencias Sociales.

García Álvarez, Alejandro (1990): La gran burguesía comercial en Cuba, 1899-1920, La Habana, Editorial de Ciencias Sociales.

García López, José Ramón (1992): Las remesas de los emigrantes españoles en América. Siglos XIX y XX, Barcelona, Ediciones Júcar.

GuttérREZ I POCH, Miquel (1994): «Tradición y cambio tecnológico: la industria papelera española, 1750-1936», en NADAL, J. y CATALAN, J.(eds.), La cara oculta de la industrialización española. La modemización de los sectores no lideres (siglos XIX y XX), Madrid, Alianza, pp. 341-368.

Hernández Sandoica, Elena (1982): Pensamiento burgués y problemas coloniales en la España de la Restauración, 1875-1887, Madrid, Universidad Complutense.

LABRA, Rafael M. de (1901): La crisis colonial de España, 1869-1898, Madrid, Tipografía de Alfredo Alonso. 
Maluquer de Motes, Jordi (1974): «El mercado colonial antillano en el siglo XIX», en Nadal, J. y Tortella, G. (eds.), Agricultura, comercio colonial y crecimiento económico en la España contemporánea, Barcelona, Ariel, pp. 322-357.

- (1992): Nación e inmigración: los españoles en Cuba (ss. XIX y XX), Barcelona, Ediciones Júcar.

Martínez Carrión, José Miguel (1989): «Formación y desarrollo de la industria de conservas vegetales en España, 1850-1935», Revista de Historia Económica, 3, pp. 619-649.

Moreno Fraginals, Manuel (1978): El ingenio. Complejo económico social cubano del azúcar, La Habana, Editorial de Ciencias Sociales.

NADAL, Jordi (1987): «La industria fabril española en 1900. Una aproximación», en NadAl, J.; Carreras, A. y Sudria, C. (comps.), La economía española en el siglo XX. Una perspectiva bistórica, Barcelona, Ariel, pp. 23-61.

- (1994): «La transición del zapato manual al zapato "mecánico" en España», en NADAL, J. y CataláN, J. (eds.), La cara oculta de la industrialización española. La modemización de los sectores no líderes (siglos XIX y XX), Madrid, Alianza, pp. 321-339.

NARANJO Orovio, Consuelo (1992): «Trabajo libre e inmigración española en Cuba: 1880-1930», Revista de Indias, 195-196, pp. 749-794.

OrTEGa VALCÁRCEL, José (1990): «La industrialización en Cantabria (1844-1944). Génesis de una industria especializada», en NADAl, J. y Catalán, J. (dir.), Pautas regionales de la industrialización española (siglos XIX $y X X$ ), Barcelona, Ariel, pp. 79.105.

Peris Mencheta, Francisco (1993): De Madrid a Panamá (1. ed. en 1886), Valencia, Generalitat Valenciana.

Piqueras, Juan (1985): La agricultura valenciana de exportación y su formación bistórica, Madrid, Instituto de Estudios Agrarios, Pesqueros y Alimentarios.

PORTell VIlA, Herminio (1939): Historia de Cuba en sus relaciones con los Estados Unidos y España, La Habana, Jesús Montero Editor.

PRADOS DE LA EsCoSURA, Leandro (1982): Comercio exterior y crecimiento económico en España, 1826-1913: tendencias a largo plazo, Madrid, Banco de España.

- (1988): De Imperio a nación. Crecimiento y atraso económico en España (1780-1930), Madrid, Alianza.

ROBLEDO, Ricardo (1988): «Crisis agraria y éxodo rural: emigración española a ultramar, 1880-1920», en GaRRABOU, Ramón (ed.), La crisis agraria a fines del siglo XIX, Barcelona, Crítica, pp. 212-244.

Roig De Leuchsenring, Emilio (1949): Cuba y los Estados Unidos, 1805-1898, La Habana, Sociedad Cubana de Estudios Históricos e Internacionales.

SAIz PASTOR, Candelaria (1988): «El modelo colonial español durante el siglo XIX: un debate abierto», Estudios de Historia Social, 44-47, pp. 651-655.

- (1994): «El colonialismo español en el Caribe durante el siglo Xux: el caso cubano, 1833-1868», en Naranjo Orovio, C. y Mallo Gutiérrez, T. (eds.), Cuba, la perla de las Antillas. Actas de las I Jornadas sobre Cuba y su bistoria, Aranjuez, Doce Calles, pp. 213-221.

SUDRIA, Carles (1983): «La exportación en el desarrollo de la industria algodonera española, 1875-1920», Revista de Historia Económica, 2, pp. 369-386. 
VAlDALISO, Jesús M. (1991): Los navieros vascos y la marina mercante en España, 1860-1935. Una bistoria económica, Bilbao, HAEE/Instituto Vasco de Administración Pública.

Zambrana Pineda, Juan Francisco (1985): «El olivar español, 1870-1930», en Garrabou, Ramón y SAnZ, Jesús (eds.), Historia agraria de la España contemporánea, 2, Expansión y crisis (1850-1900), Barcelona, Crítica, pp. 301-320.

ZANETTI, Óscar (1975): «El comercio exterior de la República neocolonial», en Pérez de la Riva, Juan, et al., Anuario de estudios cubanos, 1, La República neocolonial, La Habana, Editorial de Ciencias Sociales, pp. 45-126.

- (1989): Los cautivos de la reciprocidad. La burguesia cubana y la dependencia comercial, La Habana, Ministerio de Educación Superior. 